\title{
FOREIGN DEPARTMENT
}

\author{
Ix cruzas or
}

LAVINIA L. DOCK

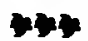

\section{A PIONEER IN DANISH NURSING}

A NURSING pioneer whose work has all been of an entirely original character-that is, thought out by her unaided self, not suggested by others, is Mrs. Norrie, of Denmark, who, since the London Congress, has been the honorary vice-president of the International Council from Denmark. Mrs. Norrie's own actual experience of nursing has been short, for when, as a young woman of superior family position, she desired to learn nursing, it was with difficulty, and struggling against obstacles, that she succeeded in getting some months' hospital work with instruction from the physicians.

She soon after married Dr. Norrie, a physician of prominence (and related to those New York Norries who are interested in St. Luke's Hospital) and of unusually liberal views, and, herself possessing a creative and fearless mind, she has worked continuously since her marriage, in writing, in speaking, and by her influence, for the best interests of nursing education and a better systematization of hospital management.

A curious feature of the Danish hospitals is, that while the hospitals are admirable and the nurses of such a beautiful and excellent type of young womanhood that no training-school superintendent could wish for more ideal probationers, these lovely nurses get practically no teaching, as we understand the word.

The matron or principal of the training-school, as we see her in England and America, holding all the threads in her hand and regarding it as her duty to see that all of her pupils, so nearly as may be, have equal opportunities in all the different services-seems to be distinguished by her absence in many of these fine European hospitals. The head nurses remain in their posts for a long time and become a set of little independent rulers. They do not like to have the nurses changed, and the doctors cannot tolerate the idea. There is no one to systematize and carry out an orderly, well-planned scheme of training for all, and, consequently, there is no such thing in existence; of course, the physicians imagine that there is, but that is only because they don't know what nurses should be taught. 
It is certainly most interesting, in these old countries, where men have everything their own way, to see just what funny ways they have. However, this is not to the point.

Mrs. Norrie, hoping to interest well-educated women in nursing and to enter a wedge for systematic education, opened in 1883 an elementary nursing course for gentlewomen, secured lecturers on hygiene, and obtained for these pupils seven hours of practical work in hospitals for a three-months' course.

She next presented, in written articles, a plan for a genuine nursing school, for which she adrocated the following principles: 1, a probationary or preliminary period; 2, shorter hours (than fourteen); 3, a systematic scheme of training; also, classes in elementary nursing for mothers of families. Her plan was, for three months to give the pupils the elements of nursing, of anatomy and physiology, chemistry, hygiene, and dietetics, and then for second three months to put them through laundry, kitchens, and linen-room. After this she adrocated a full ward course of two and one-half years in hospital, with experience in medical and surgical work, children's wards, mental cases, and obstetrics.

Her idea was to have the preliminary course open to day pupils living at home. Mrs. Norrie has written much against long hours, and her ideas have appeared in Swedish and German magazines, as well as English.

She has made some interesting historical studies in nursing affairs, showing that in 1625 the number of nurses provided for military hospitals was much more ample (one to ten patients) than was the case at the end of the last century, when only one to twenty patients was the rule. Mrs. Norrie's chief life-work, however, has been in the field of the woman's movcment, and in this connection she has long adrocated an idea which also grew spontaneously as the result of her work and reflections-namely, that, just as in European countries, all young men in every grade of life must give their country at least one year of military service, from which they are only exempt through ill-health or some unusual condition-so also there should be required of all young women, of every grade of society, one year of public service or service given to the State, which should be credited to them as the equivalent of the military service, which, when it is given by the educated classes, is called (though really compulsory) "voluntary." Her idea for this public service is, of course, that it shall be a useful service, either in schools, or hospitals, or in ways not as yet developed. This idea has spread far and wide among women in European countries, who suffer especial injustice under the taunt, often made, that they arc useless to the State, whereas men are its defenders. In countries where there is no compulsory military service 
this discrepancy is, of course, not so glaring as in Europe, where militarism is a fetich. Whether this really splendid idea will ever be carried out remains to be seen.

An anecdote of Mrs. Norrie's early nursing days will give a good idea of how nurses have had to pick up knowledge in the past. It occurred in a children's hospital, where the nurses, in order to learn catheterization, were accustomed to practise it on little girls, although the little patients did not need it and it was in no way ordered. Yet this zeal on the nurses' part to learn was considered most commendable and was approved highly by the physicians, to one of whom Mrs. Norrie ventured modestly to dissent, saying she thought it was bad for the children; he inquired why she thought so, and she stated that she thought it produced cystitis. He assured her with some warmth that children did not have cystitis, and she then, to defend herself, took him to inspect several children.

The result was that he wrote a learned paper proving the existence of cystitis in little girls following the use of the catheter, which made a great impression in the medical society. However, Mrs. Norrie's name was not mentioned!

Mrs. Norrie was also at the Berlin Congress, but her duties in the Executive Committee allowed her little time for nursing affairs. Although all her work is done most quietly, the influence of her broadmindedness and sweet temperateness of character has been greater than many people know.

\section{ST. JOHN'S HOUSE, LONDON,}

Beldevue nurses who are interested in nursing history may not, perhaps, all know just where the roots of their tree run back to in the past.

In speaking to Miss Monk, the matron of King's College Hospital, of the supposition that Sister Helen, who started the Bellevue TrainingSchool, was from the King's College Hospital, I learned that Sister Helen, though she had been in charge at King's College Hospital for a time, was in reality a member of the Church of England Order of St. John's House, which has a most interesting and admirable history in the development of English nursing. The British Journal of Nursing, which is a mine of nursing history, has in its issue of May 30, 1889 (it was then the Nursing Record), a letter, dated from St. John's House and signed K. H., which gives a sketch of the pioneer work of this order.

It appears that a letter had been written by Dr. R. B. Todd in 1847, 
urging the necessity of nursing reform and of educated women to take up the work.

In July, 1848, many eminent men (women not mentioned), including physicians, met and established an "Institution for Training Nurses for Hospitals, Private Families, and the Sick Poor," and called it "St. John's House." The prospectus for the proposed institution, with the scheme for probationers, nurses, and sisters, was published in the British Magazine for July, 1848.

The first St. John's Nurses were trained at Westminster Hospital, and when the Crimean War broke out St. John's House had trained nurses ready to go to the front with Miss Nightingale.

In 1856 the sisters and nurses of St. John's House undertook the nursing of King's College Hospital. This has since been discontinued, as the hospital has now its own training-school.

The early history of St. John's House is to be found in its early reports, in the London newspapers for July, 1848, and for October, 1854, and in "In Memoriam, R. B. Todd," by Dr. Lionel Beale.

Miss Mary Burr, a nurse who was trained in St. John's House, and who was at the Berlin Congress, is a peculiarly sympathetic personality, and gives one the feeling of having known her a long time. She writes occasionally and excellently on nursing affairs, and I am sure that this impression of having known her before, which I mentioned long ago in the JOORNAL, is some occult result of her belonging to this institution which started our dear old Bellevue in the way it should go.

\section{NURSES' HOUSE IN PARIS}

Miss Sarah Macdonald, of the Johns Hopkins Hospital, has lived in Paris for several years, where she, with several other nurses, made a charming and cosey little home in a flat at 10 Rue d' Alger, just off the Tuileries Gardens and close to the very centre of Paris. She and the little group of nurses have plenty of private duty all the time, and this winter they have enlarged their borders, taken a larger flat in the same house, and Miss De Long, of the Johns Hopkins, is taking charge of the coöperative affairs. They will have a directory for English and American nurses, choosing them, of course, carefully. Their telephone number is 297-88. Three more Johns Hopkins nurses have joined them, and, though permanent residents will probably only be taken after direct arrangement in America, they hope to have room sometimes for nurses who are passing through Paris to stay for a few days. Such visitors will surely find the hospitality and comfort of the little nursing home most attractive, and on the working side it is quite certain to be a success. 


\section{ITEMS}

IN looking over the back numbers of the Nursing Record (now British Journal of Nursing), it is interesting to find that, at a quarterly meeting of the Royal British Nurses' Association held in August, 1890, Dr. Bedford Fenwick said that he had received the rules and papers of the "American Nurses' Association" and proposed a resolution of congratulation and best wishes, with offer of friendly counsel if needed, to the American society. Not only that, but the resolution was seconded by Miss Catherine J. Wood, whom American nurses learned to know and respect at Buffalo, and passed by acclamation.

What American Nurses' Association was this?

From the same source we learn that one of the earliest suggestions of hourly nursing was made by Miss Louisa Twining, a name well known to English people, but whose noble life of philanthropic labor for the improvement of workhouse infirmaries is known too little in America. In 1888 she wrote: "The District Nursing Association begun three years ago at Kensington, being a branch of the Central Home in Bloomsbury Square, nurses the poor in their own homes, and visits once or twice daily, going to people in flats, lodgings, or boarding-houses, largely a class of tradespeople, who pay in accordance with their means. ... I am quite sure that when the system of daily visits has become known it will be extended to the upper classes as well . . . as there is now so large a number of ladies trained as nurses ... I venture to direct their attention to this hitherto unexplored field of work."

AT a recent meeting of the National Council of Women of England Miss Catherine Wood (Women's Local Government Society) moved a resolution bringing before the Local Government Board the urgency of the need for the appointment of women as Poor Law inspectors, more especially of Poor Law schools and of the sick wards of county unions, and the importance of the appointment of women as inspectors of the female sides of asylums for lunatics and imbeciles. Miss Wood held that work done without the coöperation of women was only half done.

IT has been the practice for nurses connected with the Liverpool District Nursing Association to visit certain of the schools and to dress any wounds, etc., needing attention. Last year some fifty thousand such dressings were performed, and the District Nursing Association desire that their work should be supported by the authorities. All connected 
with the schools-inspectors, managers, and teachers-have everything to say in favor of the good work done by the nurses, and it is to be hoped they will attain the recognition which they seek.

Nursing Reporm in France.-The municipal authorities of Bordeaux, as a result of Dr. Anna Hamilton's years of work in nursing reforms, have established a training-school on modern lines with an English sister in charge. The directrice of the newly organized Training-School for Nurses at the Hôpital du Tondu, Bordeaux, is Miss Catherine Elston, who was trained at the London Hospital, where she held the position of sister. She was subscquently appointed home sister at the Poplar Hospital. In 1903 Miss Elston was appointed cheftaine (sister) at the Maison de Santé Protestante, Bordeaux, and in April of the present year took the direction of the Nursing School at the Hôpital St. André, where the nuns and lay nurses worked together. When it was decided to separate the lay and religious elements, Miss Elston was appointed directrice at the Hôpital du Tondu, to which the lay section of the school was transferred. The hospital contains one hundred and twenty beds, and the nursing staff includes the directrice, three cheftaines, two staff nurses, twelve pupils, and a home sister. Miss Elston warmly appreciates the work done by her late chief, Dr. Anna Hamilton, for the improvement of nursing in Bordeaux is due in the first instance to her thesis, "Considerations sur les Infirmières des Hôpitaux."

A Nurses' Debating Society.--The following is the synopsis of subjects for discussion by the Debating Society connected with the League of St. John's Nurses, London, for 1905 :

"The Nursing of Tuberculosis in the Open Air, with Special Reference to People of Moderate Means;" "The Right Use of Books ;" "The Nursing of Gastro-Interotomy;" "What Opportunities have Private Nurses for Self-Improvement?" "What are the Duties of a Nurse in Preparing for an Operation in a Private House?" "Influenza and its Complications." "Is Nursing a Profession? If Not, Why Not?" "Should Nurses Spend Their Holidays in Professional Company or Not?" "Why are Private Nurses so Iittle Able to Adapt Themselves to Circumstances?"

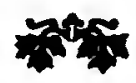

